atropellando, ni andar estorbando la tarea que en un momento dado hace el jefe. El que se siente verdaderamente único, está también seguro de que ha de llegarle su turno de ser jefe y entonces podrá exigir de los demás esa misma lealtad en la cooperación que él haya sabido prestar cuando iba a la cola en el deporte infantil de seguir al jefe, o en la tarea social de trabajar para una institución o para alguna empresa. El destino mismo a menudo se venga de los que descuidan la tarea secundaria y rara vez les encomienda el mando.

Esfuerzo que sólo nos lleva a sobresalir entre los demás es un esfuerzo estéril, destructivo, a menudo criminal y es siempre esfuerzo de hombre que no confía en sí mismo, de hombre inepto; en cambio, el esfuerzo realmente varonil, aún cuando sea muy individualista, tenderá a la realización de una tarea superior a la vanagloria individual, superior al interés del individuo; esfuerzo que no puede realizarse sin la cooperación leal del grupo de la sociedad, de las gentes todas de una época.-J OS É VA S C O N E L OS.

Exclusivo para Atenea en Chile.

\title{
El estilo y la composición en la obra de Marcel Proust
}

(9) ROUST ya pasó, Proust es uno de tantos y nadie lo toma ahora en cuenta.» Oír esta frase en París cuando hace apenas tres años que apareció el último volumen de su obra maravillosa, causa irritante sorpresa. Como se comprende, fué enunciada por uno de estos papagayos que repiten de café en café las estupideces que sueltan a tontas y a locas los grupitos de «fracasados» que se forman aquí y allá, los que, no pudiendo levantar una obra propia, emplean su tiempo tratando de derribar la ajena. Lo terrible es que estos grupitos son los que se agitan, meten bulla y salen resultando verdaderos vocingleros de la fama.

Para describir a este tipo del crítico (o, más bien, criticador) vocinglero, cuadran admirablemente las palabras de Nietzsche en su lapidario capítulo «De las moscas de la plaza pública» (Así hablaba Zaratustra) que por falta de espacio siento citar sólo fragmentariamente: 
El cómico tiene espíritu, pero poca conciencia del espíritu. Cree siempre en aquello por lo cual hace creer más enérgicamente, creer en él mismo.

Mañana tiene una fe nueva y pasado mañana otra más nueva. Posee sentido rápidos como el pueblo y temperaturas variables.

Derribar: a eso llama demostrar. Volver loco: a eso llama convencer. Y la sangre es para él el mejor de todos los argumentos.

Llama mentira y nada a una verdad que no penetra más que en oídos finos. Verdaderamente él no cree más que en dioses que hagan mucho ruido en el mundo.

¿Pierde Proust al "no estar de moda»? Me parece que al contrario. No ha escrito para el populacho y está bien que el populacho reniegue de él.

Más que la frase: "Proust ya pasó de moda» me dolió oír un día: «Ay! Proust, qué regio!» No, Proust no puede, no debe ser ni «regio", ni "macanudo".

Como queda aún un grupo de gente que lo lee todavía, sea por goce o para discutirlo, pero esto seriamente, cual conviene entre gente honrada, me permitiré hablar un poco de él, a mi manera, aunque ésta sea mala e indigna del gran tema que me solicita.

Nada me desconcierta tanto como oír o leer que la lectura de Proust es aburridora; que su estilo es pesado; que tiene «de longueurs désespérantes». Si se le lee materialmente, tan sólo, con los ojos, lo comprendo; pero si a cada palabra, a cada frase se le da su significado, ya no entiendo; pues pocos hombres han dicho más cosas interesantes y de una manera más concisa.

Para que no se me tilde de paradójica cuando me atrevo a afirmar que Proust tiene un estilo conciso, invito a reflexionar unos instantes sobre lo que es la concisión del estilo. A mí me parece que ella consiste en no emplear sino las palabras rigurosamente necesarias para expresar el pensamiento. Ahora, si el pensamiento es complejo, sutil, variado, simuoso; dominado constantemente por la perspectiva de una cuarta dimensión, el tiempo, que lo obliga a retroceder y adelantar, aludiendo al pasado y al porvenir junto con el presente, la frase podrá ser larga... y concisa A UN MISMo TIEMPO. Será larga por el hecho de abarcar muchas cosas; y concisa porque las dirá del modo más corto sin que nada le falte, sin embargo, para su comprensión exacta.

Esta frase larga de Proust tiene el original encanto de quitarle a sus penetrantes observaciones el carácter dogmático del aforismo (aunque contienen, ellas, toda la profundidad de los mejores). Ha venido a probar elocuentemente, además, 
que no siempre lo corto es lo sintético, sino que proviene de lo esencial; y que, a veces, es el detalle lo esencial (y el detalle escondido: Lineo no reparó en la corola exuberante de las flores ni en el follaje de los árboles para llegar a su magnífica clasificación botánica.)

En Proust, la visión de la vida es, a un mismo tiempo, la de un hombre de ciencia, de un psicólogo, de un filósofo y de un artista que colaboran siempre; de manera que, al traducir cuatro versiones diferentes de un mismo tema, es natural que la escritura se prolongue, sin que esto signifique prolijidad de estilo, aunque sí de pensamiento. De aquí me parece provenir la confusión: se le achaca al estilo de Proust lo que se le debería achacar a su pensamiento ( $\mathrm{si}$ es que se le pueda reprochar al pensamiento el ser profundo y vasto). Me imagino que ningún autor ha tenido más conciencia para pasar su frase por el tamiz hasta que ni un solo término sobre. Es el clasicista por excelencia. Nunca se le encuentra una redundancia; nunca un cliché una frase de cajón, una sola palabra escapada al azar de la pluma o que venga a servir de relleno o balanceo musical a la frase. Jamás se contenta con un *à peu près». No se abandona, es siempre dueño de sí mismo y, en consecuencia, de su lector a quien domina completamente: es imposible leerlo con interpretaciones personales porque carece de toda vaguedad $\mathrm{u}$ obscuridad que las permitan. La consideración de esto me llevaría a afirmar una segunda aparente paradoja: Proust se distingue por la claridad del estilo. Es verdad que hay claridades que nos deslumbran porque nuestra vista es débil y preferimos, antes que acostumbrarnos a ellas con el fin de ver bien lo que iluminan, cerrar los ojos diciendo que no se ve nada o que todo es turbio.

Proust es difícil, sí; pero esto es otra cuestión. La ley del menor esfuerzo no rige para leerlo. No podemos, con él, soñar por cuenta propia: va, lámpara en mano, señalándonos $s u$ camino y diciéndonos cómo hay que mirarlo. Ahora, a nosotros nos toca tener los pulmones fuertes y el pie firme del buen excursionista, porque el viaje ha de ser largo, entre paisajes accidentadísimos y deberemos salvar los pequeños obstáculos de sus frases y escalar las montañas de sus ccôtés antes de alcanzar el maravilloso panorama de su pensamiento total.

La excepcional memoria de Proust ha sido su hilo de Ariadna, sin el cual no habría podido ejecutar los continuos movimientos de acercamiento y alejamiento necesarios para encarar y dominar las distintas perspectivas de su construcAtenea.-13 
ción gigantesca; sólo porque nosotros no poseemos igual memoria y al leerlo nos perdemos con frecuencia en el dédalo, primero de sus frases, segundo de sus «côtés», creemos a primera vista en la obscuridad de sus períodos y en la falta de unidad de la obra. Mas la composición de ella está en proporción y perfectamente adaptada al vasto tema que trata. Sería ridículo exigirle que se angostara a las antiguas medidas de las obras unilaterales que en nada se le pueden comparar porque ésta es completamente original y, por consiguiente necesitó crear su forma adecuada (o, más bien dicho, su forma iba implícitamente contenida en el fondo, como debe suceder siempre que los autores tengan la sinceridad y la audacia de hacer las cosas como deben y no al revés).

A la recherche du temps perdu este título, genial «trouvaille», no es fantasista como parece en el primer momento; no ha sido inventado para «epatar» al burgués. Se le ha impuesto al autor mismo que (hay que hacerlo notar) tiene la modestia de considerar al artista como a un traductor; no como a una especie de improvisador. Este irreemplazable título viene, una vez más, a probarnos el espíritu de síntesis de su autor: es la coronación magnífica de esta obra única.-M A G D A E NA PET I T.

\section{La Doctrina de Monroe}

TNTERROGADO sobre incidencias tan ruidosas como recientes, alguien formuló hace poco una definición inesperada:

- La Doctrina de Monroe es un enigma.

$\mathrm{Y}$ acaso traducen esas palabras una realidad.

Lo que maravilla cuando estudiamos el origen del célebre postulado, o cuando lo seguimos en sus evoluciones múltiples, es la impericia perseverante de que dieron prueba ante él los gobiernos de la América Latina. Ni comprendieron el significado, ni calcuilaron las consecuencias, ni vigilaron la aplicación. El árbol se alimentó con la savia de los que debían ser sus víctimas, y nadie indagó en beneficio de quién se desarrollaba, qué frutos debía dar, o hasta dónde alcanzaría su sombra.

Ciegos, sordos, mudos, los dirigentes dejaron que obrara la naturaleza, que en política suele tener abundancias de selva virgen. Sólo cuando las raíces levantaron los cimientos del propio suelo natal, parecieron empezar a darse cuenta de que algo ocurría. Pero ya era tarde. De aquí que nos encontremos a hora ante 